\title{
Characterization of porcine partially reprogrammed iPSCs from adipose-derived stem cells
}

\author{
Chao Wei ${ }^{*}$ Xia Li ${ }^{*}$, Pengfei Zhang ${ }^{*}$, Yu Zhang, Tong Liu, Shaoshuai Jiang, Fei Han \\ and Yunhai Zhang \\ Anhui Provincial Laboratory for Local Livestock and Poultry Genetic Resource Conservation and Breeding, \\ College of Animal Science and Technology, Anhui Agricultural University, Hefei, Anhui 230036, China \\ Correspondence should be addressed to Y Zhang; Email: yunhaizhang@ahau.edu.cn \\ ${ }^{*}$ (C Wei, X Li and P Zhang contributed equally to this work)
}

\begin{abstract}
Partially reprogrammed induced pluripotent stem cells (PiPSCs) have great potential for investigating reprogramming mechanisms and represent an alternative potential material for making genetically modified animals and regenerative medicine. To date, PiPSCs have scarcely been reported in detail when compared with mice and humans. In this study, we obtained PiPSCs from porcine adipose-derived stem cells (pADSCs) by ectopic expression of human transcription factors (OCT4, SOX2, c-MYC, and KLF4) in feeder-free condition. The morphology and proliferation activity of porcine PiPSCs (pPiPSCs) were similar to those of porcine fully reprogrammed iPSCs (pFiPSCs); furthermore, pPiPSCs expressed higher levels of the typical surface molecules (CD29) found in pADSCs. However, pPiPSCs were negative for key proteins (NANOG) connected with stemness and possessed lower differentiation ability in vivo and in vitro. When differentiationinhibiting factors were withdrawn, pPiPSCs-derived cells (pPiPSC-DCs) showed similar features to pADSCs in many aspects, including proliferation, differentiation, and immunosuppression. When both types of cells were used to produce cloned embryos, we found that the blastocyst formation rate of 19DC (one of the pPiPSC-DC cell lines)-derived cloned embryos was obviously higher than that of others. The total cell number of 19DC-derived blastocysts was significantly higher than the 30DC (one pFiPSC-DC cell line)-derived blastocysts. In all, through limited differentiation ability, the proliferation activity of pPiPSCs is similar to that of pFiPSCs, and pPiPSCs can retain several of the features of pADSCs, which are beneficial to cell therapy. Furthermore, the differentiation of pPiPSCs is more favorable for producing high-quality reconstructed embryos.

Free Chinese abstract: A Chinese translation of this abstract is freely available at http://www.reproduction-online.org/content/149/5/ 485/suppl/DC2.

Reproduction (2015) $\mathbf{1 4 9} 485-496$
\end{abstract}

\section{Introduction}

Terminally differentiated somatic cells can be reprogrammed to induced pluripotent stem cells (iPSCs) by ectopic expression of transcription factors (Takahashi \& Yamanaka 2006). Pluripotent genes such as NANOG, POU5F1, and FBXO15 are activated after the completion of reprogramming. These genes can be combined with drug-resistant genes to screen pluripotent cell lines. Fbxo15 was the first gene used for this process (Takahashi \& Yamanaka 2006), while it was activated at the early stage of reprogramming. In this study, most cells were partially reprogrammed, although these cells exhibited some of the features of fully reprogrammed iPSCs (FiPSCs) (Okita et al. 2007). These cells expressed only partially pluripotent factors and their promoter regions of OCT4 (Takahashi \& Yamanaka 2006) and NANOG (Park et al. 2008) were highly methylated. Meanwhile, only a portion of specific genes in somatic cells were downregulated and persistent expression of exogenous genes is necessary to maintain their pluripotency. They could not embed into blastocysts (Takahashi \& Yamanaka 2006), and chimeric and tetraploid blastocyst-complemented animals cannot be obtained (Silva et al. 2008). Owing to the above characteristics, these cells were termed partially reprogrammed iPSCs (PiPSCs) (Rodriguez et al. 2012). In fact, most of the reprogrammed cell clones generated by POU5F1, SOX2, KLF4, and MYC were PiPSCs (Yu et al. 2007). Although PiPSCs are less pluripotent than FiPSCs, they also exhibit faster neural differentiation than FiPSCs, which decrease the risk of oncogenicity associated with FiPSCs (Matsui et al. 2012). PiPSCs represent an intermediate stage of reprogramming and can be used to research mechanisms and blocks in the reprogramming procedure (Silva et al. 2009, Plath \& Lowry 2011). However, to our knowledge, 
no studies have analyzed the characteristics of porcine PiPSCs (pPiPSCs) thus far.

iPSCs have been shown to possess cellular memory after differentiated cells were reprogrammed (Sullivan et al. 2010). Reprogramming memory includes two aspects. First, after the completion of reprogramming, iPSCs partially retain the transcriptional and epigenetic features of donor cells. At the transcriptional level, some specific genes of donor cells are still expressed in iPSCs. For instance, Polo et al. (2010) demonstrated that granulocytederived iPSCs expressed high levels of genes typically found in granulocytes, such as lysozyme and gr- 1 . Bar-Nur et al. (2011) found that, at the epigenetic level, $\beta$ cell-derived iPSCs maintain a partially open chromatin structure on the promoter regions of insulin, $\mathrm{Pdx} 1$, and Mafa, and certain cell-derived iPSCs shared the methylation and acetylation patterns of the promoter region and histone within their parent cells (Polo et al. 2010). Secondly, when the differentiation-inhibiting factors of iPSCs were removed, iPSCs tended to differentiate into their donor cells. Hu et al. (2010) reported that iPSCs derived from human retinal pigmented epithelial (RPE) cells spontaneously differentiated back into RPE cells after the removal of FGF2; this phenomenon has also been verified in human pancreatic islet $\beta$ cells (Bar-Nur et al. 2011). Owing to multiple differentiation potency (Huang et al. 2012) and low immunogenicity (Yanez et al. 2006), adipose-derived stem cells (ADSCs) possess promising clinical applications. No study has reported whether PiPSCs hold more reprogramming memories as partially reprogrammed cells. Further investigation is required to determine whether porcine ADSC (pADSC)-derived PiPSCs could retain more of the features of pADSCs that are beneficial for clinical application.

As ESCs have high proliferation activity and differentiation potency, they are ideal materials for gene modification (Gropp et al. 2003) and regenerative medicine (Darabi et al. 2008). Currently, as no bona fide in vitro porcine ESCs are available, porcine iPSCs (PiPSCs) were used as the candidate cells. Application of PiPSCs in agriculture and human medicine involves gene modification and generation of transgenic pigs by the somatic cell nuclear transfer (SCNT) or chimeric method, and whether research into porcine iPSCs could contribute to perfect culture systems of porcine ESCs should also be explored. West et al. (2011) established chimeric pigs from mesenchymal stem cell (MSC)-derived iPSCs, and, although this was controversial, it has been suggested that MSC-derived iPSCs may be beneficial for the generation of porcine offspring. Fan et al. (2013) studied iPSCs and differentiated porcine iPSCs, and concluded that the expressions of exogenous transcription factors in porcine iPSCs have a negative effect on the production of iPSC-derived clone pigs. Accordingly, we wonder whether pADSC-derived PiPSCs with the perfect regulation exogenous gene expression are beneficial for the development of SCNT embryos.
Therefore, we aimed to establish PiPSCs from pADSCs, characterize their features, and generate highquality reconstructive embryos from pPiPSCs.

\section{Materials and methods}

\section{Ethics statement}

All animal procedures were approved by the Animal Health Care Committee of Anhui Agricultural University.

\section{Chemicals}

All chemicals were purchased from Sigma unless otherwise stated.

\section{Source of pADSCs and FiPSCs}

pADSCs and FiPSCs (C4-6 and C4-30 naïve-like PiPSCs (NpiPSCs)) were established in our previous study (Zhang et al. 2014).

\section{Lentiviral production and transduction}

Human embryonic kidney (HEK)-293T cells were plated at $90 \%$ confluence in a T-25 flask. The cells were transfected with $3.6 \mu \mathrm{g}$ of each lentiviral vector (OCT4,SOX2, KLF4, and $c-M Y C$ ) plus $1.8 \mu \mathrm{g}$ pVSV-G plasmid and $2.7 \mu \mathrm{g}$ delta 8.91 using Fugene HD (Roche). The culture medium was replaced with $4 \mathrm{ml}$ of fresh medium after $24 \mathrm{~h}$. The supernatant containing the lentivirus was harvested $48 \mathrm{~h}$ after transfection and centrifuged at $800 \mathrm{~g}$ for $5 \mathrm{~min}$ to pellet the cell debris. The supernatant containing lentivirus was then transferred and stored at $2-8{ }^{\circ} \mathrm{C}$ for a week.

pADSCs were plated $\left(2500\right.$ cells $\left./ \mathrm{cm}^{2}\right)$ in feeder-free condition and incubated with doxycycline (Dox)-inducible lentiviral vectors carrying reprogramming factors (OCT4, $S O X 2, c-M Y C$, and KLF4). After $48 \mathrm{~h}$, the cells were passaged onto Matrigel (BD Bioscience Pharmingen, San Diego, CA, USA)-coated plates and cultured in a growth medium for an additional $24 \mathrm{~h}$. Then, the growth medium was replaced with an induction medium composed of DMEM, 15\% fetal bovine serum (FBS, Life Technologies, Carlsbad, CA, USA), $2 \mathrm{mM}$ L-glutamine (Life Technologies), $0.1 \mathrm{mM}$ nonessential amino acids (Life Technologies), $50 \mu \mathrm{g} / \mathrm{ml}$ vitamin C, $1 \mathrm{mM}$ sodium pyruvate (Hyclone, Logan, UT, USA), $0.1 \mathrm{mM}$ $\beta$-mercaptoethanol (Life Technologies), $2 \mu \mathrm{g} / \mathrm{ml}$ Dox, $1000 \mathrm{U} / \mathrm{ml} \mathrm{mLif}$ (Chemicon, Millipore, Temecula, CA, USA), and $4 \mathrm{ng} / \mathrm{ml}$ basic fibroblast growth factor (bFGF, Perprotech, Rocky Hill, NJ, USA). The colonies were picked after 8 days and maintained for subsequent cultures.

\section{Karyotype analysis}

pPiPSCs at passage 10 were treated with $0.1 \mu \mathrm{g} / \mathrm{ml}$ colchicine for 3.5-4 h. The trypsinized cells were then treated with $0.075 \mathrm{M}$ $\mathrm{KCl}$ at $37^{\circ} \mathrm{C}$ for $25 \mathrm{~min}$, fixed with methanol:acetic acid (v/v, $3: 1$ ) fixative for $20 \mathrm{~min}$ with shaking, centrifuged at $200 \mathrm{~g}$ for 
$8 \mathrm{~min}$, and most of the supernatant was discarded. This fixing procedure was repeated twice. After the last centrifugation, a drop of the cell suspension was placed onto a cold microscope slide, heated briefly by passing the slide over a flame two to three times, and stained with Giemsa dye. At least 20 metaphase cells were analyzed under the microscope. DNA content analysis of pPiPSCs was performed according to the method described in our previous study (Wei et al. 2013).

\section{Alkaline phosphatase staining and immunostaining}

Alkaline phosphatase (AP) staining was performed according to the manufacturer's instructions (Millipore). For immunostaining, pPiPSCs were fixed with 4\% formaldehyde in Dulbecco's PBS (DPBS) for $15 \mathrm{~min}$, permeabilized with 1\% Triton X-100 in DPBS for $15 \mathrm{~min}$, and blocked with $2 \%$ BSA in DPBS for $1 \mathrm{~h}$. Then, the cells were incubated with primary antibodies for $1 \mathrm{~h}$, including antibodies against OCT4 (1:200 dilution, Abcam), NANOG (1:150 dilution, R\&D Systems, Minneapolis, MN, USA), SSEA3 (Ascites, 1:400 dilution, Developmental Studies Hybridoma Bank), and SSEA4 (Ascites, 1:400 dilution, Developmental Studies Hybridoma Bank, DSHB, lowa City, IA, USA). The primary antibodies were detected using secondary antibodies conjugated to Alexa Fluor 488 (1:200 dilution, Molecular probes, Eugene, OR, USA) and Alexa Fluor 594 (1:200 dilution, Molecular Probes).

\section{Quantitative PCR and RT-PCR}

Total RNA and cDNA of each sample were prepared using the RNeasy Mini Kit (Qiagen) and QuantiTect Reverse Transcription Kit (Qiagen), respectively, according to the manufacturers' protocols. Quantitative PCR (qPCR) was performed in a Step One Plus Real-Time PCR System (Applied Biosystems). FastStart SYBR Green Master (Roche) was used for PCR, and GAPDH was chosen as an endogenous control. cDNA samples were subjected to PCR amplification with primers for GAPDH, POU5F1, SOX2, CDH1, LIN28A, DNMT3B, ESRRB, DPPA2, CCL2, LGALS1, MMP1, and MMP8 (Supplementary Table S1, see section on supplementary data given at the end of this article). For RT-PCR, the cDNA samples were subjected to SOX9, PDX1, NES, NEUROD1, CD40, CD86, MICA, and GAPDH (Supplementary Table S2).

\section{Embryoid body and teratoma formation}

For embryoid body (EB) formation, iPSCs were treated with TryPLE, and 10000 cells were transferred to ultra-low attachment six-well plates in suspension culture containing equal amounts of iPSC medium and differentiation medium (which is composed of DMEM/F12, 20\% knockout serum replacement (KSR), $2 \mathrm{mM}$ L-glutamine, $0.1 \mathrm{mM}$ nonessential amino acids, and $0.1 \mathrm{mM} \beta$-mercaptoethanol). All cell lines were used six times and the culture medium was changed every 3 days. After 3 days, the amounts of EBs were counted in a 96-well plate with appropriate dilution and the EB formation efficiency of iPSCs was analyzed. After 9 and 14 days, total RNA was extracted from the EBs and used for RT-PCR.
For teratoma formation, $5 \times 10^{5} \mathrm{pFiPSCs}$ and pPiPSCs were injected into nonobese diabetic/severe combined immunodeficient (NOD/SCID) mice to induce teratoma formation. Tumors were harvested 4 months after injection.

\section{Spontaneous differentiation of pFiPSCs and pPiPSCs}

After 12 passages, the pFiPSCs and pPiPSCs were dissociated with TryPLE (Life Technologies) and plated without a feeder layer and Matrigel, and the culture medium was replaced with DMEM/F12 containing $10 \%$ FBS, $50 \mu \mathrm{g} / \mathrm{ml}$ vitamin C, and $10 \mathrm{ng} / \mathrm{ml} \mathrm{bFGF}$. The cells were then cultured at $37{ }^{\circ} \mathrm{C}$ in the presence of $5 \% \mathrm{CO}_{2}$ in a humidified incubator. The culture medium was replaced every 3 days until 80-90\% confluence was achieved. The pFiPSC-derived cells (pFiPSC-DCs) and pPiPSC-derived cells (pPiPSC-DCs) were continuously passaged until replicative senescence was confirmed.

\section{Cell surface markers}

Flow cytometry was used to analyze the expression of the surface markers on pFiPSCs, pPiPSCs, and their derivatives. The cells were treated with FITC-conjugated, PE-conjugated, and AF647-conjugated MABs against CD29 (BD Pharmingen), CD44 (eBioScience, San Diego, CA, USA), CD90 (BD Pharmingen), and CD105 (BD Pharmingen). Nonspecific antibody binding was eliminated by isotype controls. The cells were harvested and washed thrice with DPBS, and divided into aliquots of $\sim 5 \times 10^{5}$ cells/sample. The cells were then incubated with primary antibodies at $4{ }^{\circ} \mathrm{C}$ for $30 \mathrm{~min}$. After washing, the cells were resuspended in 1\% paraformaldehyde and analyzed by flow cytometry (BD FACS Calibur, Becton-Dickinson, San Jose, CA, USA). Data were analyzed using the Flowjo software (Treestar Inc, Ashland, OR, USA).

\section{Adipogenesis and osteogenesis of pPiPSC-DCs and pFiPSC-DCs}

Six days after pPiPSC-DCs and pFiPSC-DCs were cultured in vitro, they were cultured in human MSC adipogenic differentiation medium (Cyagen Biosciences, Guangzhou, China) and human MSC osteogenic differentiation medium (Cyagen Biosciences) for adipogenesis and osteogenesis, respectively, according to the manufacturer's protocols. Triglycerides in derivative cells were stained with oil red $\mathrm{O}$, and loaded oil red O was extracted with isopropanol, after which the absorbance of the extract was measured at a wavelength of $510 \mathrm{~nm}$ in a spectrophotometer. Successful osteogenesis was detected by staining the mineralization nodules of the differentiated cells with alizarin red $\mathrm{S}$.

\section{Isolation of mouse spleen peripheral blood mononuclear cells}

Spleens were isolated from 8-week-old male ICR mice and washed with pre-cooled DPBS three times. The organs were then crushed with a syringe needle to release cells. The obtained cell suspension was then filtered twice through an 
$80-\mu \mathrm{m}$ mesh to remove tissue debris, and the suspension was centrifuged at $300 \mathrm{~g}$ for $5 \mathrm{~min}$ and resuspended with $40 \%$ Percoll (GE Pharmacia, Piscataway, NJ, USA). This new cell suspension was gently added to the top of $70 \%$ Percoll in a $15-\mathrm{ml}$ centrifuge tube, centrifuged at $800 \mathrm{~g}$ for $20 \mathrm{~min}$ at room temperature and zero acceleration in a horizontal centrifuge. The cells that were located between 40 and $70 \%$ Percoll were carefully pipetted out and washed three times with DMEM/F12 containing 5\% FBS, then incubated in $3 \mathrm{ml}$ of red blood cell lysate for 4 min on ice. After being washed three times, cell survival was estimated with trypan blue staining, and the cells were then cultured in a basic medium containing RPMI-1640 (Life Technologies), 10 mM HEPES (Hyclone), and $10 \%$ FBS.

\section{Co-culture of pPiPSC-DCs and pFiPSC-DCs with mouse spleen peripheral blood mononuclear cells}

pPiPSC-DCs and pFiPSC-DCs at passages 1 and 3 and pADSCs were inactivated using mitomycin $C(M M C)$ and plated in a 96-well plate at 1,2 , and $4 \times 10^{4}$ cells/well as stimulator cells (experiment groups A, B, and C). After 48 h, 200- $\mu$ l aliquots of basic medium containing $1 \times 10^{5}$ freshly isolated peripheral blood mononuclear cells (PBMCs) were added to the wells as response cells, and the wells were divided into the following groups: experiment group A contained PBMCs, $1 \times 10^{4}$ stimulator cells, and $2.5 \mu \mathrm{g} / \mathrm{ml}$ concanavalin (ConA); experiment group B contained PBMCs, $2 \times 10^{4}$ stimulator cells, and $2.5 \mu \mathrm{g} / \mathrm{ml}$ ConA; experiment group C contained PBMCs, $4 \times 10^{4}$ stimulator cells, and $2.5 \mu \mathrm{g} / \mathrm{ml}$ ConA; negative control group 1 containing different concentrations of stimulator cells; and negative control group 2 containing PBMCs without ConA. After incubation for $48 \mathrm{~h}$, the inhibition ratio (IR) of each experiment group was measured using 3-(4,5-dimethyl-2-thiazolyl)-2,5diphenyl-2-H-tetrazolium bromide (MTT) method.

\section{Somatic nuclear transfer}

Oocyte collection and maturation were conducted as described previously (Zhou et al. 2014). Briefly, porcine cumulus-oocyte complexes (COCs) were collected from 3- to 6-mm ovarian follicles, and COCs with uniform ooplasm and at least three layers of cumulus cells were cultured at $38.5^{\circ} \mathrm{C}$ in $5 \% \mathrm{CO}_{2}$ and maximum humidity to allow the emission of the first polar body in porcine in vitro maturation (PIVM) medium (composed of tissue culture medium 199 supplemented with $15 \%$ FBS, $10 \%$ porcine follicular fluid, $10 \mathrm{IU} / \mathrm{ml}$ of eCG (Intervet, Boxmeer, Holland), $5 \mathrm{IU} / \mathrm{ml}$ of hCG (Intervet), $0.8 \mathrm{mM}$ L-glutamine, and $0.05 \mathrm{mg} / \mathrm{ml}$ gentamicin). After IVM for $42 \mathrm{~h}$, the COCs were treated with $1 \mathrm{mg} / \mathrm{ml}$ hyaluronidase to remove the surrounding cumulus cells. The oocytes were then enucleated by removing the first polar body and the surrounding $10 \%$ cytoplasm in micromanipulation buffer media containing tissue culture medium 199 plus 2\% FBS and $5 \mu \mathrm{g} / \mathrm{ml}$ cytochalasin B under an inverted microscope (Olympus IX-71) equipped with micromanipulation system (Narishige, Setagaya-ku, Tokyo, Japan). Meanwhile, smooth, strongly refractive donor cell from passage 3 was injected into the perivitelline space of the enucleated oocyte to reconstruct donor cell-oocyte cytoplasm couplets. In each group, $\sim 50$ COCs were used for reconstruction of embryos, and the transfer was repeated four times for each group.

For fusion and activation, the reconstructed couplets were sequentially treated by two direct current pulse of $1.65 \mathrm{kV} / \mathrm{cm}$ with a 1 -s interval and chemically assisted activation medium consisting of porcine zygote medium 3 (PZM-3) plus $10 \mu \mathrm{g} / \mathrm{ml}$ cycloheximide and $10 \mu \mathrm{g} / \mathrm{ml}$ cytochalasin B. Embryo cleavage and blastocyst development were observed and documented at days 2 and 6 respectively. The harvested blastocysts were fixed in $4 \%$ paraformaldehyde at room temperature for $15 \mathrm{~min}$. After the blastocysts were washed three times in DPBS, they were incubated in DPBS containing $1 \mu \mathrm{g} / \mathrm{ml}$ of 4',6-diamidino-2-phenylindole (DAPI) for $10 \mathrm{~min}$. The total cell number of blastocysts in each group was recorded by observation under an inverted microscope.

\section{Statistical analysis}

Data are expressed as means \pm S.E.M., and the differences between groups were evaluated using SPSS version 17.0. Statistical significance was set at $P<0.05$.

\section{Results}

\section{Generation of pPiPSCs}

After induction medium was added to the lentiviraltransfected pADSCs, phase contrast and immunofluorescence imaging revealed the presence of small flat colonies at day 3 (Fig. $1 \mathrm{~A}$ and B). Eight days after induction, the colonies were selected and split into fresh feeder cells. New colonies, which shared the packed dome morphology and had a rough colony surface, were formed in 2 days (Fig. 1C and D) and stained negative for AP (Fig. 1E), while pFiPSCs stained positive for AP (Fig. 1F). Two pPiPSCs cell lines, namely, C4M3-19 and C4M3-21, were analyzed in our study. The proliferative activities of both lines were similar to that of our previous pFiPSCs (Zhang et al. 2014) (Fig. 1G), and pPiPSCs could be expanded to more than 40 passages without senility. Karyotype analysis demonstrated normal morphology in 38 chromosomes (Fig. 1H). Compared with pADSCs, the DNA content of pPiPSCs ranged from 0.9 to 1.1 , and there were no obvious differences between pPiPSCs and pFiPSCs (Fig. 1I).

\section{Limited pluripotency of pPiPSCs}

Immunostaining, RT-PCR, and in vitro differentiation were performed to characterize the pluripotency of pPiPSCs. Immunostaining results revealed that pPiPSCs express OCT4, SSEA3, and SSEA4 but not NANOG (Fig. 2A), while OCT4, SSEA3 and SSEA4, and NANOG were expressed in pFiPSCs (Zhang et al. 2014). At the mRNA level, genes associated with multipotency in pPiPSCs, such as DNMT3B,CDH1, OCT4, and SOX2, were expressed at higher levels than those in pADSCs but 

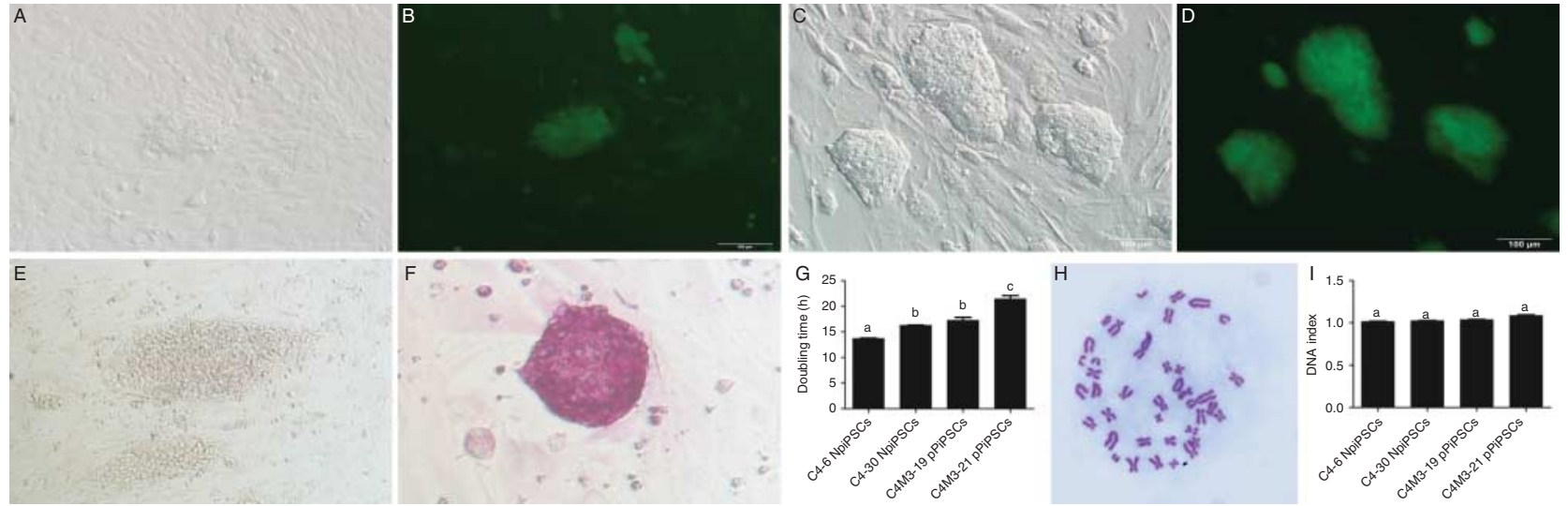

Figure 1 Reprogramming of pPiPSCs. (A) Bright field microscopic analysis of cells 3 days after induction. (B) Immunofluorescence imaging to detect enhanced green fluorescent protein (EGFP) expression of cells 3 days after induction. (C) Bright field microscopic analysis of cells 2 days after passage. (D) Immunofluorescence imaging to detect EGFP expression of cells 2 days after passaging. (E) AP staining of pPiPSCs. (F) AP staining of pFiPSCs. (G) Doubling time of pFiPSCs and pPiPSCs. Different superscripts above the bars denote significant difference $(P<0.05)$. $(H)$ Morphology and number of chromosomes in pPiPSCs. (I) DNA index of pPiPSCs.

at lower levels than those in pFiPSCs. Genes associated with complete reprogramming, including LIN28, ESRRB, and DPPA2, were expressed at high levels in pFiPSCs but at low levels in pPiPSCs (Fig. 2B). The capacity of EB formation was analyzed to evaluate the differentiation of cells in vitro. Similar to pFiPSCs, pPiPSCs also possessed the ability of forming EBs (Fig. 2C). Among the pFiPSC lines, C4M3-21 showed a significantly lower efficiency of $E B$ formation, while the $E B$ formation efficiency of C4M3-19 was significantly higher than that of C4-30 NpiPSCs, and was comparable to that of C4-6 NpiPSCs (Fig. 2D). After spontaneous differentiation in vitro for 9 days, markers from three germ layers, such as $P A X 6$, NESTIN, NEUROD, and SOX9, could be detected in pFiPSC-derived EBs but not in the pPiPSC-derived EBs. At day 14 , only mesoderm marker SOX9 was detected in pPiPSC-derived EBs, while PAX6, NESTIN, and NEUROD were undetectable (Fig. 2E). For in vivo teratoma formation, mature teratomas were generated from pFiPSCs after 4 months while pPiPSCs did not form any teratomas (Fig. 2F and G).

\section{Reprogramming memory of pPiPSCs at the level of reprogrammed cells}

Reprogramming memory is also the focus of iPSCs research as it might have an effect on immune rejection and cellular developmental potential. In this part, to examine the reprogramming memory in pADSC-derived iPSCs, typical pADSC markers, including CD29, CD90, CD44, and CD105, in pPiPSCs and pFiPSCs were analyzed by flow cytometry (Supplementary Figure S1, see section on supplementary data given at the end of this article). All markers were highly expressed in pADSCs, but only CD29 was detected in both pPiPSC lines. However, only one of the two pFiPSC lines expressed CD29. The proportion of CD29-positive cells was significantly lower in both pPiPSCs and pADSCs, although it was higher than the corresponding levels in C4-6 NpiPSCs (Fig. 3A). The expression intensity of pPiPSCs was indistinguishable from that of pADSCs, but it was significantly higher than that of C4-6 NpiPSCs (Fig. 3B).

Genes involved in immunity were evaluated in pPiPSCs. MHC-I mRNA was expressed in pPiPSCs but not in pFiPSCs. Co-stimulatory molecules, including CD40 and CD86, were not expressed in both types of cells (Fig. 3C). Low levels of galectin 1 was observed in both pPiPSCs and pFiPSCs, while the MMP8 expression level in pPiPSCs was higher than that in pFiPSCs (Fig. 3D).

\section{pPiPSC-DCs possessed more typical features of pADSCs than pFiPSC-DCs}

When differentiation-inhibiting factors, including Dox, Lif, bFGF, and $2 \mathrm{i}$, were withdrawn from the medium, the cells showed obvious differentiation after $24 \mathrm{~h}$, and all cells exhibited uniform morphology after $72 \mathrm{~h}$. Similar to pADSCs, C4M3-19 pPiPSC-DCs (19DCs) and C4M3-21 pPiPSC-DCs (21DCs) showed fibroblast-like morphology and could continuously expand to more than 20 passages without significant senility. However, primary C4-6 NpiPSC-DCs (6DCs) and C4-30 NpiPSCDCs (30DCs) exhibited epithelial-like morphology, which changed to fibroblast-like morphology after passage, and the cells ceased proliferation in five passages (Fig. 4A). When pPiPSC-DCs and pFiPSC-DCs were re-plated in new dishes at a very low density, pPiPSC-DCs proliferated in a colony-like fashion and pFiPSC-DCs exhibited irregular morphology and gradually became senescent and ceased to expand (Supplementary Figure S2A and B, see section on supplementary data given at the end of this article).

pADSCs can differentiate into osteoblasts and adipocytes after induction. To evaluate the multipotency 

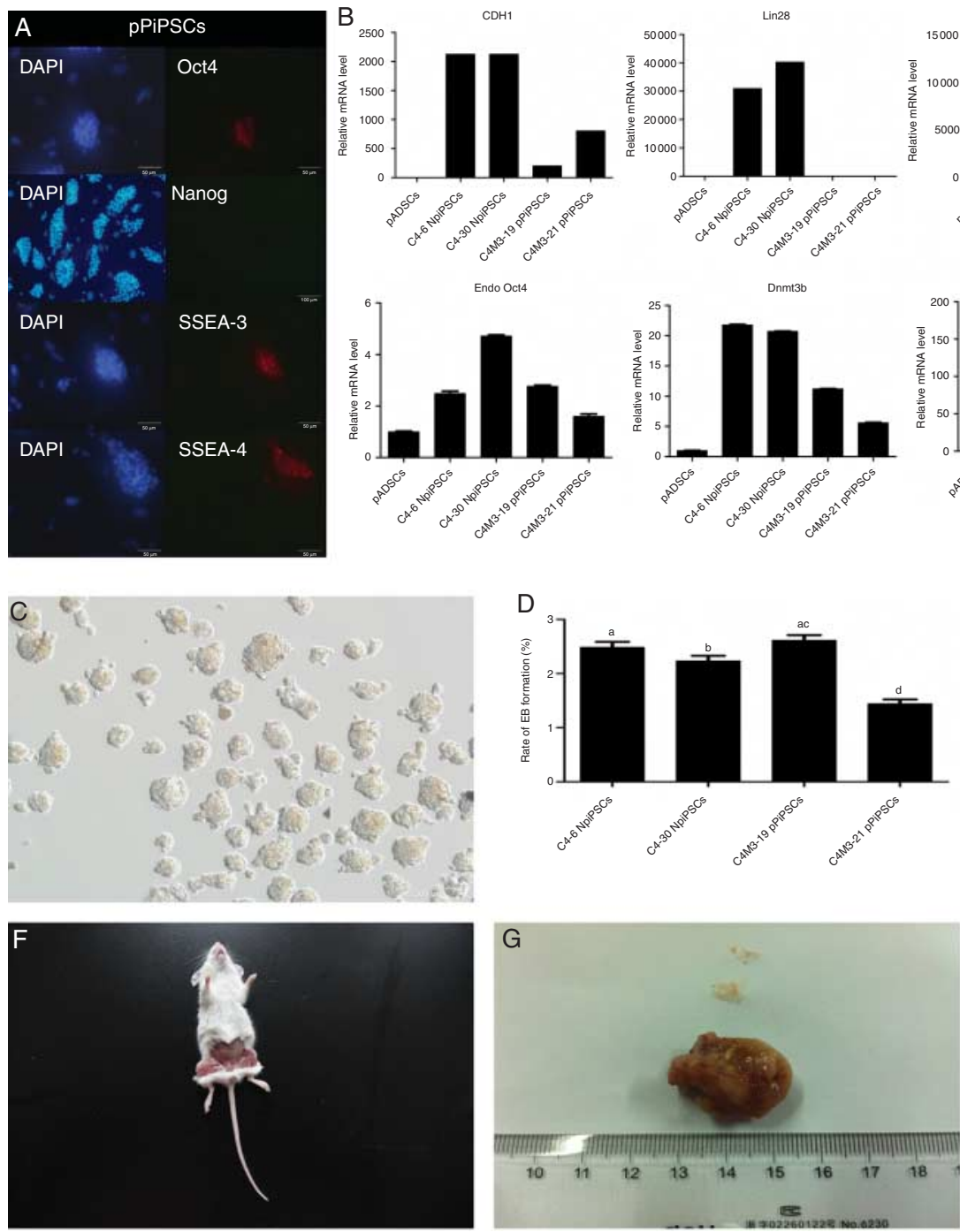
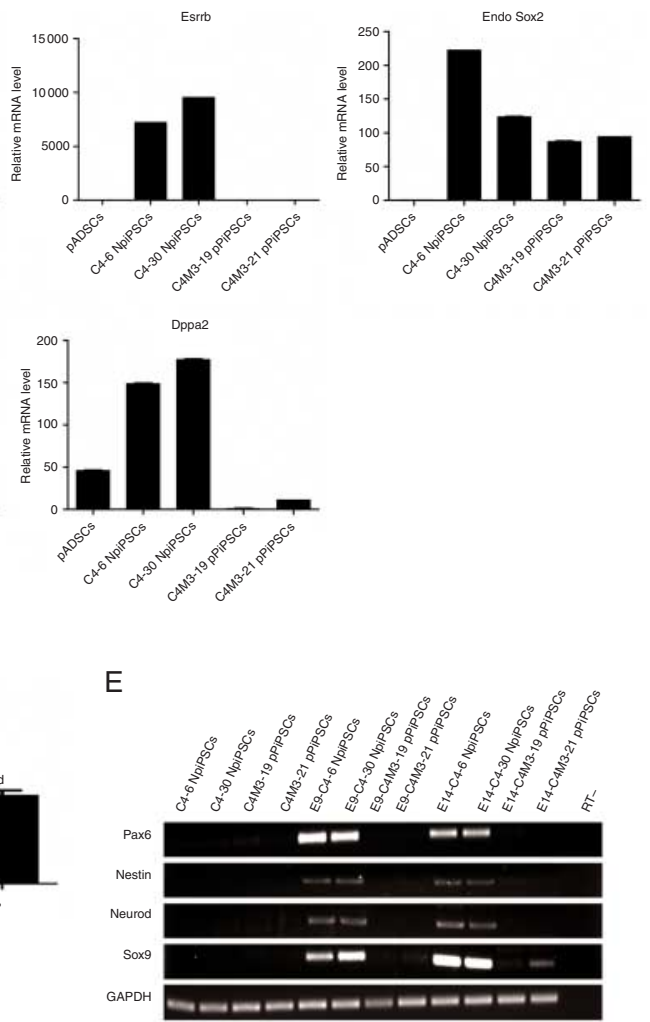

Figure 2 Pluripotency of pPiPSCs. (A) Immunostaining of pluripotency markers in pPiPSCs. (B) qRCR analysis of genes correlated with pluripotency and full reprogramming. (C) EB formation of pPiPSCs. (D) Efficiency of EB formation of pPiPSCs. Different superscripts above the bars denote significant difference $(P<0.05)$. (E) Expression of markers from three germ layers in pPiPSCs by RT-PCR. (F) Teratoma formation ability of pPiPSCs. (G) Teratoma formation ability of pFiPSCs.

of pPiPSC-DCs, cells were cultured in adipogenic and osteogenic induction media. After 21 days in adipogenic medium, most pADSCs could be stained with oil red $\mathrm{O}$ and form mature adipocytes, pPiPSC-DCs were filled with multiple fat droplets but did not form mature adipocytes, and only single droplets were observed in pFiPSC-DCs (Fig. 4B). To measure the efficiency of adipogenic induction, isopropanol was utilized to extract the oil red $\mathrm{O}$ from differentiated cells, and the OD of pPiPSCs-DCs was lower than that of pADSCs but higher than that of pFiPSC-DCs (Fig. 4C). After culture in osteogenic medium, pPiPSC-DCs formed typical mineralized calcium deposits but pFiPSC-DCs did not (Fig. 4D).

The typical surface markers correlated with pADSCs were analyzed in pPiPSC-DCs. pPiPSC-DCs were positive for CD29, CD44, and CD90, and negative for CD105, while pFiPSC-DCs were positive only for CD29 and CD44 (Supplementary Figure S3, see section on supplementary data given at the end of this article). There was no significant difference between pPiPSC-DCs and pFiPSC-DCs for CD29, while the positive rate of CD44 was remarkably higher in pPiPSC-DCs than in pFiPSCDCs (Fig. 4E). Moreover, pPiPSC-DCs also possessed a higher expression intensity of CD29 than pFiPSC-DCs, as well as that of CD44 in 19DCs (Fig. 4F).

\section{Immunological characteristics of pPiPSCs-DCs}

RT-PCR was used to detect the expression of some of the genes correlated with immunogenicity. The results revealed that MHC-I was expressed in both pFiPSC-DCs and pPiPSC-DCs. Slight expression of CD40 was observed in pPiPSC-DCs and pFiPSC-DCs. CD86 was not expressed in either pFiPSC-DCs or pPiPSC-DCs 

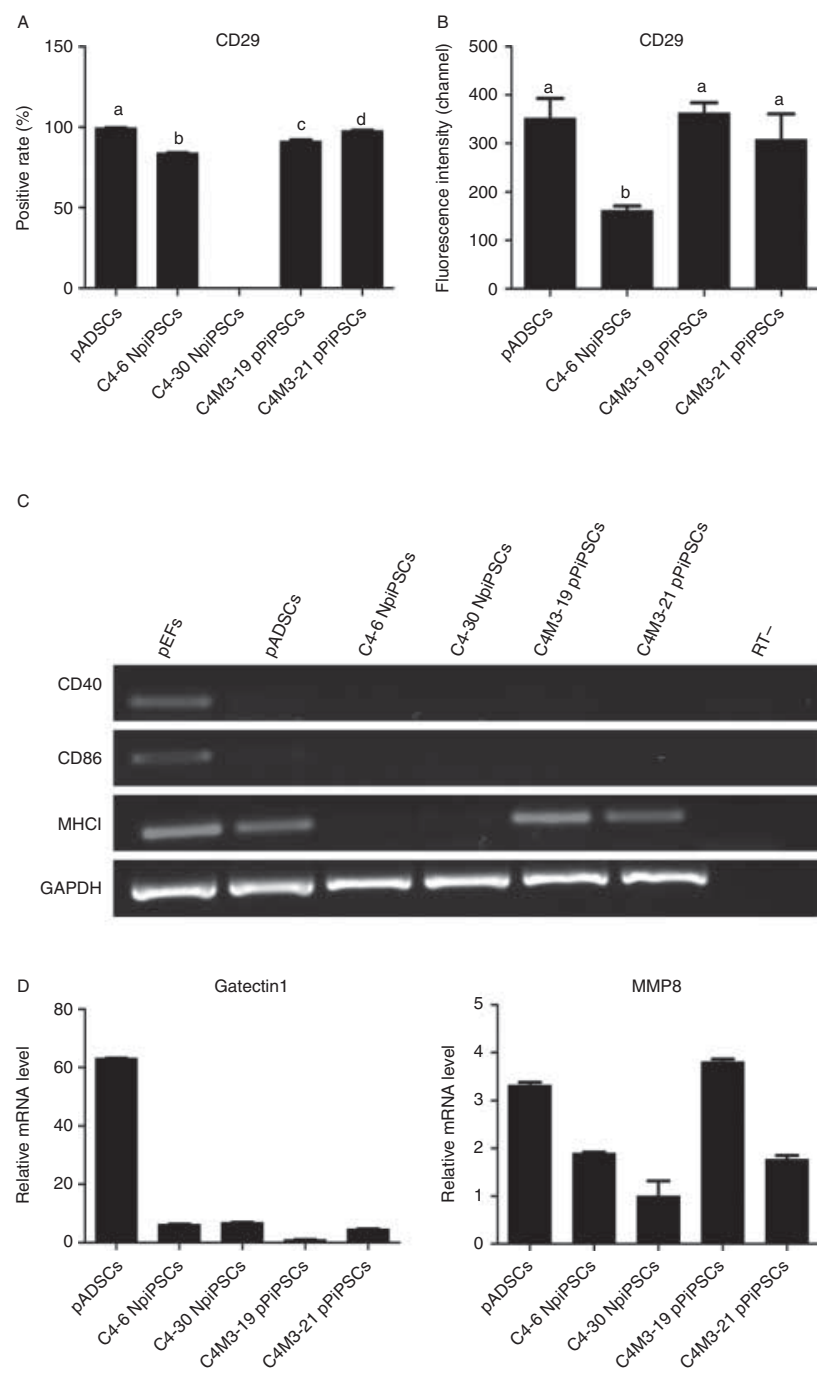

Figure 3 Reprogramming memory of pPiPSCs in the undifferentiated state. (A) Positive rate of CD29 in pPiPSCs and pFiPSCs. (B) Mean fluorescence intensity of CD29 in pPiPSCs and pFiPSCs. (C) Expression of genes correlated with immunogenicity in pPiPSCs and pFiPSCs; porcine embryonic fibroblasts (pEFs) were the positive control. (D) Expression of genes correlated with immunosuppression in pPiPSCs and pFiPSCs as analyzed by qPCR. Different superscripts above the bars denote significant difference $(P<0.05)$.

(Fig. 5A). Genes related to immunosuppression were estimated by qPCR, and the results revealed that the expression level of CCL2 was higher in pPiPSC-DCs than in pFiPSC-DCs (Fig. 5B). To investigate the immunosuppression ability of pPiPSC-DCs and pFiPSC-DCs functionally, $10^{5}$ PBMCs were co-cultured with different numbers of stimulating cells at different passage. At passage 1, each cell line suppressed the proliferation of mouse spleen lymphocytes; this effect increased with the number of stimulator cells. There were no significant differences between pPiPSC-DCs and pFiPSC-DCs with the same number of stimulator cells. However, at passage 3, the IR value of pPiPSC-DCs was significantly higher than that of pFiPSC-DCs in general, especially in the case of 19DCs (Fig. 5C and D).

\section{pPiPSC-DCs supported the development of SCNT embryos to a greater extent than pFiPSC-DCs}

In order to determine whether these cells supported the development of cloned embryos, both pPiPSC-DCs and pFiPSC-DCs were used as donor cells to generate reconstructed embryos by SCNT. Detailed data and information for the NT experiments are presented in Supplementary Table S3, see section on supplementary data given at the end of this article. The cleavage rate of the embryos reconstructed from pPiPSC-DCs and pFiPSC-DCs showed no obvious differences (Fig. 6A). The blastocyst rate of the embryos reconstructed from 19DCs was significantly higher than that of embryos reconstructed from pFiPSC-DCs (Fig. 6B and C). The total cell number of blastocysts from 19DCs was significantly higher than that from 30DCs, and there was no obvious difference in the blastocyst cell number between 21DCs and pFiPSC-DCs (Fig. 6D).

\section{Discussion}

In this study, we successfully established pPiPSCs from pADSCs and studied their characteristics. pPiPSCs were similar to pFiPSCs in terms of morphology and proliferation activity, but the former exhibited a lower capacity of differentiation. Furthermore, pPiPSCs and their differentiated cells possessed more features similar to pADSCs, and pPiPSC-DCs could be favorably used for the development of SCNT embryos.

In reprogramming, there are many obstacles that block the generation of iPSCs from somatic cells, such as incomplete silencing of cell lineage-specific genes, methylation of DNA promoter region, and deacetylation of histone. While only a few cells can overcome these blocks and achieve complete reprogramming, most cells are arrested at the partial reprogramming stage, stopping further reprogramming (Feng et al. 2009, Mattout et al. 2011, Plath \& Lowry 2011). In this study, although the pPiPSCs and pFiPSCs were morphologically similar, the former cell lines were looser than pFiPSCs in arrangement, which might be the result of FBS. A previous study had reported that in comparison to the defined KSR, FBS prolongs the doubling time of human ESCs and decreases their number of passages and genes correlated with pluripotency (Koivisto et al. 2004). Previous studies have reported that undefined components in serum are capable of activating the Erk pathway, resulting in loss of the naïve state and differentiation (Nichols \& Smith 2009, Marks et al. 2012). These studies suggested that FBS is not beneficial for maintaining pluripotency in iPSCs or ESCs, which may favor the generation of PiPSCs. This was confirmed by the findings of the study conducted by Silva et al. (2009) who successfully 

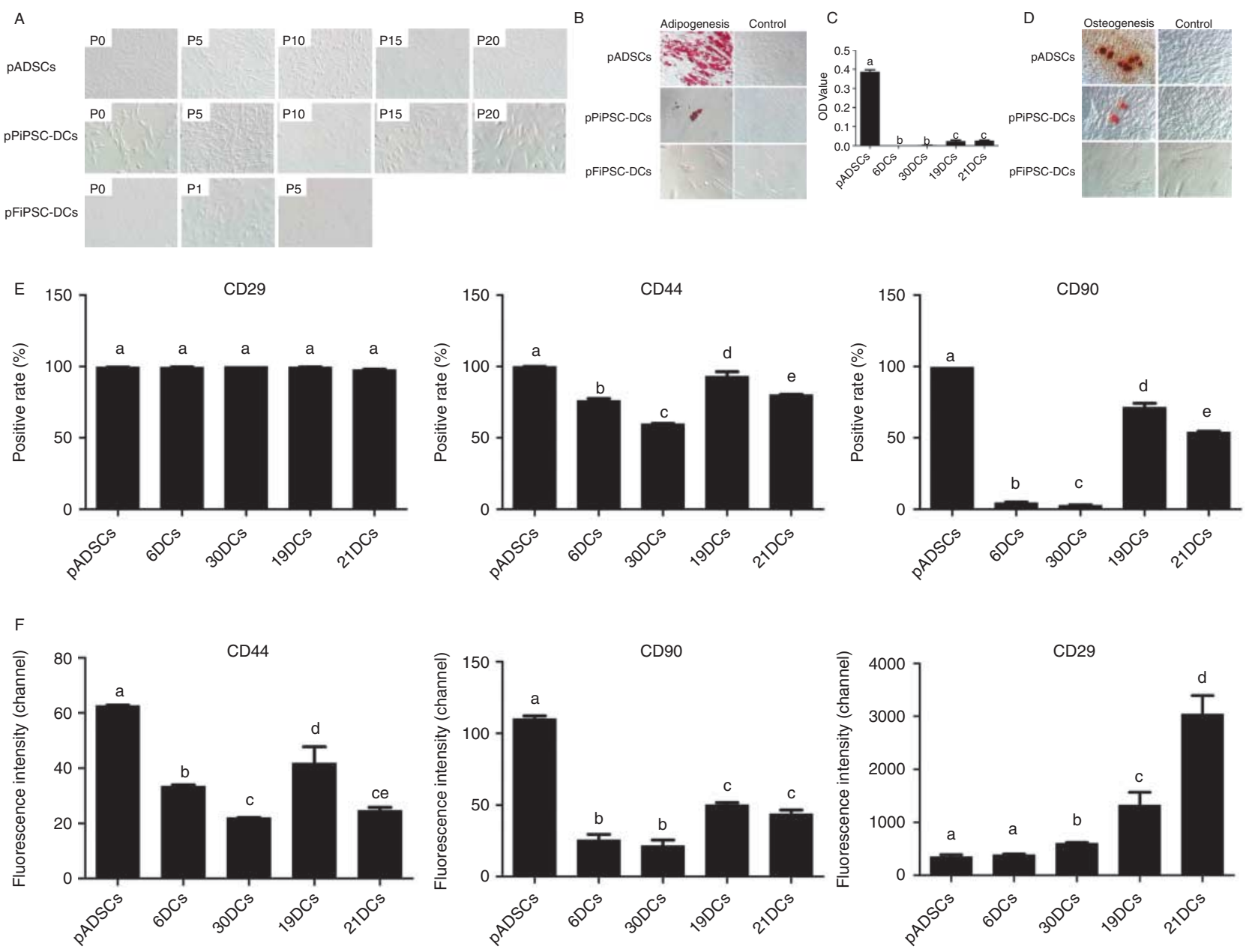

Figure 4 Reprogramming memory of pPiPSCs in the differentiated state. (A) Morphology and proliferation of pPiPSC-DCs and pFiPSC-DCs. (B) Adipogenic differentiation of pPiPSC-DCs and pFiPSC-DCs. (C) Triglyceride deposition of cells differentiated from pPiPSC-DCs and pFiPSC-DCs. (D) Osteogenic differentiation of pPiPSC-DCs and pFiPSC-DCs. (E) Positive rate of CD29, CD44, and CD90 in pPiPSC-DCs and pFiPSCS-DCs. (F) Mean fluorescence intensity of CD29, CD44, and CD90 in pPiPSCS-DCs and pFiPSC-DCs. Different superscripts above the bars denote significant difference $(P<0.05)$.

obtained PiPSCs in FBS-containing medium, while FiPSCs were obtained when PiPSCs were transferred to a serum-free medium. Thus, FBS was utilized to produce pPiPSCs in our study. Moreover, our pPiPSCs were derived in feeder-free conditions, promoting the safety of their clinical application and convenience for basic research, as the unknown components from feeders can potentially evoke immunorejection in recipients during autologous cell transplantation (Martin et al. 2005).

Although pPiPSCs share many features with pFiPSCs, certain different characteristics exist, including gene and protein expression and capacity of differentiation in vivo and in vitro. In particular, the expression levels of ESRRB, UTF1, LIN28, and DPPA2 could be considered an index to distinguish PiPSCs from FiPSCs (Pan \& Pei 2012). As reprogramming has low efficiency and is timeconsuming, it is difficult to study the sequence of events that occur during the reprogramming of the original cells to iPSCs. Pan \& Pei (2012) reported that reprogramming could be divided into two phases: an early stage and a late stage. To investigate the mechanisms of reprogramming, the original cells could be induced to a partially reprogrammed stage. By analyzing the differences between PiPSCs and FiPSCs, we can study the events that occur during the early stage of reprogramming and the factors that block further reprogramming at the late stage (Sridharan et al. 2009, Stadtfeld \& Hochedlinger 2010, Mattout et al. 2011, Plath \& Lowry 2011). These findings will then help improve the efficacy of reprogramming by removing epigenetic blocks (Mikkelsen et al. 2008) and activating signal pathways that favor reprogramming (Silva et al. 2008). In this study, OCT4, SSEA3, and SSEA4 genes were upregulated at the early stage of reprogramming from pADSCs, while NANOG was upregulated at the later stage. This finding is consistent with the results reported by a previous study, where silencing of NANOG was the key factor blocking further reprogramming of human PiPSCs (Silva et al. 2009). 

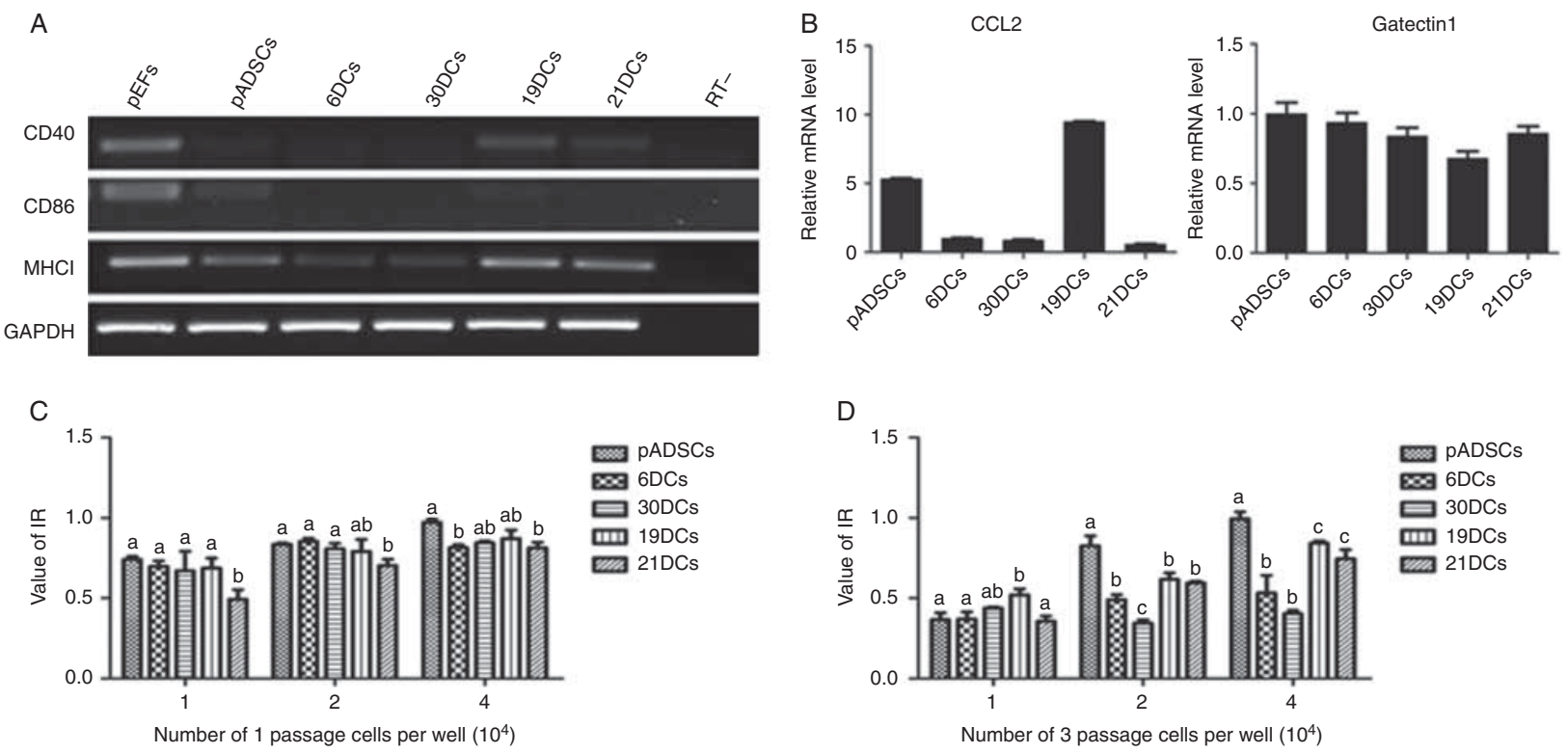

Figure 5 Immunological features of pPiPSC-DCs. (A) Expression of genes correlated with immunogenicity in pPiPSC-DCs and pFiPSC-DCs as analyzed by RT-PCR. pEFs were used as the positive control. (B) Expression of genes correlated with immunosuppression in pPiPSC-DCs and pFiPSCDCs analyzed by qPCR. (C) Capacity of pPiPSC-DCs at passage 1 to suppress the proliferation of PBMCs. (D) Capacity of pPiPSC-DCs at passage 3 to suppress the proliferation of PBMCs. Different superscripts above the bars denote significant difference $(P<0.05)$.

Thus, the upregulation of endogenous or exogenous NANOG during reprogramming may improve the generation of pFiPSCs. However, the two pPiPSC lines displayed some differences in proliferation activity, differentiation, gene expression, and development of SCNT embryos, suggesting that both cell lines underwent different degrees of reprogramming. In human PiPSCs, SSEA4-positive and SSEA4-negative PiPSCs were obtained, of which the former could transform into FiPSCs gradually during in vitro expansion. Furthermore, GDF3, hTERT, and NANOG were also expressed in the SSEA4-positive PiPSCs but not in the SSEA4-negative PiPSCs (Chan et al. 2009). Mattout et al. (2011) analyzed the epigenetic state of two mouse PiPSC lines and found that the HP1 $\alpha$ expression pattern in one mouse PiPSC line was similar to that in mouse embryonic fibroblasts (MEFs), while the HP1 $\alpha$ expression pattern in the second
PiPSC line was similar to that in FiPSCs. Thus, the degree of reprogramming affects certain features of PiPSCs.

Reprogrammed cells retain some features of their parent cells, which is termed reprogramming memory (Sullivan et al. 2010). During the reprogramming process, transcriptional and epigenetic characteristics of original cells are first downregulated, and molecules correlated with ESCs are upregulated (Plath \& Lowry 2011). As pPiPSCs are at an intermediate stage of reprogramming, we proposed a hypothesis that they may possess more features of pADSCs. Thus, pPiPSC and pPiPSC-DCs were analyzed for the presence of the basic characteristics of pADSCs (Tobita et al. 2011, Groth et al. 2012). pPiPSCs and pPiPSC-DCs expressed higher levels of surface markers than pFiPSCs and pFiPSC-DCs, suggesting that pPiPSCs had a better memory of pADSCs after reprogramming. In addition,
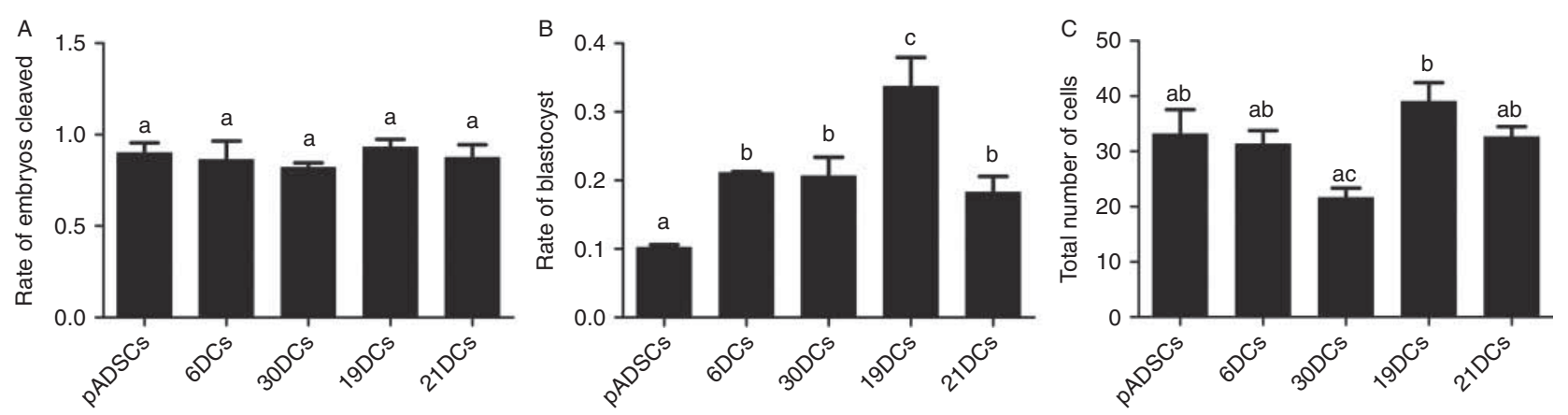

Figure 6 Development of reconstructed embryos from pPiPSC-DCs. (A) Cleavage rate of reconstructed embryos derived from pPiPSC-DCs and pFiPSC-DCs. (B) Blastocyst rate of reconstructed embryos derived from pPiPSC-DCs and pFiPSC-DCs, with the number of embryos cleaved as the denominator. (C) Total cell number in blastocysts in embryos reconstructed from pPiPSC-DCs and pFiPSC-DCs. Different superscripts above the bars denote significant difference $(P<0.05)$. 
the morphology, proliferation activity, differentiation ability, and expression level of surface markers in pPiPSC-DCs were similar to those in pADSCs, indicating that pPiPSCs could more easily differentiate back to pADSCs. However, pPiPSC-DCs were negative for CD105 and possessed a low differentiation capacity, suggesting that they may only possess some of the features of pADSCs.

Reprogramming memory may suggest incomplete reprogramming of iPSCs, while if pPiPSCs could retain the properties of original cells that could be beneficial in clinical practice or basic research, they may have useful applications. ADSCs possess the capacity of multipotency (Oswald et al. 2004, Lindroos et al. 2011), high activity of secretion (Spaggiari et al. 2009, Nguyen et al. 2010), homing (Lamfers et al. 2009), and immune modification (Yanez et al. 2006), and have been widely used in cell replacement therapy (CRT) and clinical research (Trivedi et al. 2008, Ichim et al. 2010). We questioned as to whether pPiPSCs retained these favorable characteristics after reprogramming. ADSCs strongly expressed CD29, CD44, and CD90, which are vital for the regulation of proliferation, differentiation, adhesion, migration, and tumor suppression; owing to the expression of these factors, ADSCs have become favorable candidates for clinical application (Chang et al. 1997, Rege \& Hagood 2006, Sackstein et al. 2008). pPiPSCs and pPiPSC-DCs expressed high levels of these molecules, demonstrating that these cell lines also possess these abilities. Another clinical application of ADSCs is their multipotency, which enables these cells to differentiate into various cell lineages such as adipocytes, osteoblasts, chondrocytes, and neurocytes (Safford et al. 2002, Lindroos et al. 2011). pPiPSC-DCs showed a higher level of adipogenesis and osteogenesis than pFiPSCDCs, suggesting that pPiPSC-DCs are pluripotent similar to their parent cells. Thus, in accordance with the needs of clinical practice and research, the parent cells could be reprogrammed for specific purposes. However, as PiPSCs from specific patients might retain the pathological features of their parent cells, further research should aim to determine how to erase this reprogramming memory (Polo et al. 2010).

Owing to their low immunogenicity and immunosuppression in vivo and in vitro, ADSCs can be applied in healing immunodeficiency diseases such as graft-vs-host diseases (Yanez et al. 2006), diabetes (Trivedi et al. 2008), and rheumatoid arthritis (Ichim et al. 2010). When antigens enter the body, their major histocompatibility complex (MHC) is the first to be recognized and provides the first signal of the immune response. Then, co-stimulators such as CD40, CD80, and CD86 combine with the CD28 dimer to supply the second signal, triggering the immunological response of the body (Lee et al. 2012). MHC-I and co-stimulators were not synchronously expressed in pPiPSCs-DCs and pPiPSCs, suggesting that these cell lines both possess low immunogenicity.
In vitro, ADSCs can suppress the proliferation of allogeneic PBMCs in the presence of phytohemagglutinin (PHA) or ConA. This effect is enhanced as stimulator cells increase, and it is independent of the expression of MHCs in ADSCs (Yanez et al. 2006). In vivo, ADSCs can significantly repress the immunological response of recipients to alien graft; thus, they are commonly utilized in research and to heal immune diseases such as graftvs-host disease (Yanez et al. 2006), airway allergic diseases (Cho \& Roh 2010), Alzheimer's disease (Kim et al. 2012), and acute-on-chronic liver failure (Zhu et al. 2013). In addition to allogeneic transplants, human ADSCs do not elicit immunogenic response in mouse PBMCs, and T cell infiltration did not occur when human ADSCs were transplanted in mice with Duchenne muscular dystrophy (Rodriguez et al. 2005). In this study, pADSCs and pPiPSC-DCs were both found to repress the proliferation of mouse PBMCs. Multiple secretory factors, such as transforming growth factor $\beta$ (TGF $\beta)$, prostaglandin $\mathrm{E}_{2}\left(\mathrm{PGE}_{2}\right)$, interleukin 6 (IL6), and M-CSF (Cui et al. 2007, Kilroy et al. 2007), have been reported to be involved in this process. Moreover, MSCs can suppress the proliferation and transformation of immunocytes, which requires galectin 1 to regulate the secretion of TNF $\alpha$, IFN $\gamma$, and IL2 (Gieseke et al. 2010). pPiPSC-DCs were found to express high levels of galectin 1 , which may be one of the main factors responsible for the immunosuppression effect. However, immunosuppression by pFiPSC-DCs decreased during passage, while that of pPiPSC-DCs was maintained. This may be because pPiPSC-DCs had a higher proliferation activity during in vitro culture while pFiPSC-DCs achieved senescence easily. Furthermore, the MMP-processed chemokine CCL2 inhibited plasma cells from producing immunoglobulins, which may play a role in suppressing the immune response of the recipient cells (Rafei et al. 2008); a higher level of CCL2 in pPiPSC-DCs may also contribute to this process. Thus, after reprogramming of pADSCs, the derived pPiPSCs still retain the immunological characteristics of the parent cells.

Somatic cell cloning is the only method of producing transgenic pigs from non-totipotent cells. Gene integration can be examined at a cellular level, and this method has a high success rate, and is rapid and costeffective (Deng et al. 2011). This method involves vector construction, gene modification and cell screening, embryonic development in vitro, and transplantation in vivo. High proliferation activity of pPiPSCs and their differentiated cells may satisfy the long-term requirement of in vitro cellular drug screening, although further studies are required to confirm this. During SCNT from iPSCs, insufficient silencing of exogenous genes would compromise the development of reconstructive embryos (Fan et al. 2013). Thus, differentiated cells from pPiPSCs and pFiPSCs were used for SCNT. In this study, embryos reconstructed from 19DCs via SCNT exhibited high development rate and quality, suggesting that pPiPSCs 
may be more favorable for cloning pigs than pFiPSCs. We observed that another pPiPSC line displayed indistinguishable development ability during this process, which might be the result of different degrees of reprogramming.

In summary, we established pPiPSCs from pADSCs in feeder-free condition, and studied their characteristics in detail. The pPiPSCs were found to possess high proliferation activity and limited pluripotency. In comparison to pFiPSCs, pPiPSCs retained the memory of the parent cells to a greater extent after reprogramming, especially with respect to proliferation, differentiation, and immunology, as a result of which these cells may be favorable for CRT. Furthermore, pPiPSCs were also found to be useful in the development of reconstructed embryos by SCNT, and these findings can help in the cloning of pigs.

\section{Supplementary data}

This is linked to the online version of the paper at http://dx.doi. org/10.1530/REP-14-0410.

\section{Declaration of interest}

The authors declare that there is no conflict of interest that could be perceived as prejudicing the impartiality of the research reported.

\section{Funding}

This work was supported by the National Natural Science Foundation of China (31272442).

\section{Acknowledgements}

The authors would like to gratefully acknowledge Jia Tao, Ronghua Wu, Xing Liu, Yunsheng Li, Ya Liu, and Xiaorong Zhang of our laboratory for their technical assistance.

\section{References}

Bar-Nur O, Russ HA, Efrat S \& Benvenisty N 2011 Epigenetic memory and preferential lineage-specific differentiation in induced pluripotent stem cells derived from human pancreatic islet $\beta$ cells. Cell Stem Cell 9 17-23. (doi:10.1016/j.stem.2011.06.007)

Chan EM, Ratanasirintrawoot S, Park IH, Manos PD, Loh YH, Huo H, Miller JD, Hartung O, Rho J, Ince TA et al. 2009 Live cell imaging distinguishes bona fide human iPS cells from partially reprogrammed cells. Nature Biotechnology 27 1033-1037. (doi:10.1038/nbt.1580)

Chang DD, Wong C, Smith H \& Liu J 1997 ICAP-1, a novel $\beta 1$ integrin cytoplasmic domain-associated protein, binds to a conserved and functionally important NPXY sequence motif of $\beta 1$ integrin. Journal of Cell Biology 138 1149-1157. (doi:10.1083/jcb.138.5.1149)

Cho KS \& Roh HJ 2010 Immunomodulatory effects of adipose-derived stem cells in airway allergic diseases. Current Stem Cell Research \& Therapy $\mathbf{5}$ 111-115. (doi:10.2174/157488810791268681)

Cui L, Yin S, Liu W, Li N, Zhang W \& Cao Y 2007 Expanded adipose-derived stem cells suppress mixed lymphocyte reaction by secretion of prostaglandin $\mathrm{E}_{2}$. Tissue Engineering 13 1185-1195. (doi:10.1089/ten. 2006.0315)
Darabi R, Gehlbach K, Bachoo RM, Kamath S, Osawa M, Kamm KE, Kyba M \& Perlingeiro RC 2008 Functional skeletal muscle regeneration from differentiating embryonic stem cells. Nature Medicine 14 134-143. (doi:10.1038/nm1705)

Deng W, Yang D, Zhao B, Ouyang Z, Song J, Fan N, Liu Z, Zhao Y, Wu Q, Nashun B et al. 2011 Use of the 2A peptide for generation of multitransgenic pigs through a single round of nuclear transfer. PLOS ONE 613. (doi:10.1371/annotation/22351496-73dc-4205-9d9a-95a821ae74ca)

Fan N, Chen J, Shang Z, Dou H, Ji G, Zou Q, Wu L, He L, Wang F, Liu K et al. 2013 Piglets cloned from induced pluripotent stem cells. Cell Research 23 162-166. (doi:10.1038/cr.2012.176)

Feng B, Ng JH, Heng JC \& Ng HH 2009 Molecules that promote or enhance reprogramming of somatic cells to induced pluripotent stem cells. Cell Stem Cell 4 301-312. (doi:10.1016/j.stem.2009.03.005)

Gieseke F, Bohringer J, Bussolari R, Dominici M, Handgretinger R \& Muller I 2010 Human multipotent mesenchymal stromal cells use galectin-1 to inhibit immune effector cells. Blood 116 3770-3779. (doi:10.1182/blood-2010-02-270777)

Gropp M, Itsykson P, Singer O, Ben-Hur T, Reinhartz E, Galun E \& Reubinoff BE 2003 Stable genetic modification of human embryonic stem cells by lentiviral vectors. Molecular Therapy 7 281-287. (doi:10.1016/S1525-0016(02)00047-3)

Groth A, Ottinger S, Kleist C, Mohr E, Golriz M, Schultze D, Bruns H, Mehrabi A, Schemmer P, Buchler MW et al. 2012 Evaluation of porcine mesenchymal stem cells for therapeutic use in human liver cancer. International Journal of Oncology 40 391-401. (doi:10.3892/ijo.2011. 1217)

Hu Q, Friedrich AM, Johnson LV \& Clegg DO 2010 Memory in induced pluripotent stem cells: reprogrammed human retinal-pigmented epithelial cells show tendency for spontaneous redifferentiation. Stem Cells 28 1981-1991. (doi:10.1002/stem.531)

Huang S, Wang S, Bian C, Yang Z, Zhou H, Zeng Y, Li H, Han Q \& Zhao RC 2012 Upregulation of miR-22 promotes osteogenic differentiation and inhibits adipogenic differentiation of human adipose tissue-derived mesenchymal stem cells by repressing HDAC6 protein expression. Stem Cells and Development 21 2531-2540. (doi:10.1089/scd.2012.0014)

Ichim TE, Harman RJ, Min WP, Minev B, Solano F, Rodriguez JP, Alexandrescu DT, De Necochea-Campion R, Hu XA, Marleau AM et al. 2010 Autologous stromal vascular fraction cells: a tool for facilitating tolerance in rheumatic disease. Cellular Immunology 264 7-17. (doi:10.1016/j.cellimm.2010.04.002)

Kilroy GE, Foster SJ, Wu X, Ruiz J, Sherwood S, Heifetz A, Ludlow JW, Stricker DM, Potiny S, Green P et al. 2007 Cytokine profile of human adipose-derived stem cells: expression of angiogenic, hematopoietic, pro-inflammatory factors. Journal of Cellular Physiology 212 702-709. (doi:10.1002/jcp.21068)

Kim S, Chang KA, Kim J, Park HG, Ra JC, Kim HS \& Suh YH 2012 The preventive and therapeutic effects of intravenous human adipose-derived stem cells in Alzheimer's disease mice. PLoS ONE 7 e45757. (doi:10. 1371/journal.pone.0045757)

Koivisto $\mathrm{H}$, Hyvarinen $\mathrm{M}$, Stromberg AM, Inzunza J, Matilainen E, Mikkola M, Hovatta O \& Teerijoki H 2004 Cultures of human embryonic stem cells: serum replacement medium or serum-containing media and the effect of basic fibroblast growth factor. Reproductive Biomedicine Online 9 330-337. (doi:10.1016/S1472-6483(10)62150-5)

Lamfers $M$, Idema $S$, van Milligen $F$, Schouten $T$, van der Valk $P$, Vandertop P, Dirven C \& Noske D 2009 Homing properties of adipose-derived stem cells to intracerebral glioma and the effects of adenovirus infection. Cancer Letters 274 78-87. (doi:10.1016/j.canlet. 2008.08.035)

Lee JM, Jung J, Lee HJ, Jeong SJ, Cho KJ, Hwang SG \& Kim GJ 2012 Comparison of immunomodulatory effects of placenta mesenchymal stem cells with bone marrow and adipose mesenchymal stem cells. International Immunopharmacology 13 219-224. (doi:10.1016/j.intimp. 2012.03.024)

Lindroos B, Suuronen R \& Miettinen S 2011 The potential of adipose stem cells in regenerative medicine. Stem Cell Reviews 7 269-291. (doi:10. 1007/s12015-010-9193-7)

Marks H, Kalkan T, Menafra R, Denissov S, Jones K, Hofemeister H, Nichols J, Kranz A, Stewart AF, Smith A et al. 2012 The transcriptional and epigenomic foundations of ground state pluripotency. Cell 149 590-604. (doi:10.1016/j.cell.2012.03.026) 
Martin MJ, Muotri A, Gage F \& Varki A 2005 Human embryonic stem cells express an immunogenic nonhuman sialic acid. Nature Medicine 11 228-232. (doi:10.1038/nm1181)

Matsui T, Takano M, Yoshida K, Ono S, Fujisaki C, Matsuzaki Y, Toyama Y, Nakamura M, Okano H \& Akamatsu W 2012 Neural stem cells directly differentiated from partially reprogrammed fibroblasts rapidly acquire gliogenic competency. Stem Cells 30 1109-1119. (doi:10.1002/ stem.1091)

Mattout A, Biran A \& Meshorer E 2011 Global epigenetic changes during somatic cell reprogramming to iPS cells. Journal of Molecular Cell Biology 3 341-350. (doi:10.1093/jmcb/mjr028)

Mikkelsen TS, Hanna J, Zhang XL, Ku MC, Wernig M, Schorderet P, Bernstein BE, Jaenisch R, Lander ES \& Meissner A 2008 Dissecting direct reprogramming through integrative genomic analysis (vol 454, pg 49, 2008). Nature 454 794-794. (doi:10.1038/nature07196)

Nguyen BK, Maltais S, Perrault LP, Tanguay JF, Tardif JC, Stevens LM, Borie M, Harel F, Mansour S \& Noiseux N 2010 Improved function and myocardial repair of infarcted heart by intracoronary injection of mesenchymal stem cell-derived growth factors. Journal of Cardiovascular Translational Research 3 547-558. (doi:10.1007/s12265-010-9171-0)

Nichols J \& Smith A 2009 Naive and primed pluripotent states. Cell Stem Cell 4 487-492. (doi:10.1016/j.stem.2009.05.015)

Okita K, Ichisaka T \& Yamanaka S 2007 Generation of germline-competent induced pluripotent stem cells. Nature 448 313-317. (doi:10.1038/ nature05934)

Oswald J, Boxberger S, Jorgensen B, Feldmann S, Ehninger G, Bornhauser M \& Werner C 2004 Mesenchymal stem cells can be differentiated into endothelial cells in vitro. Stem Cells 22 377-384. (doi:10.1634/stemcells.22-3-377)

Pan G \& Pei D 2012 Order from chaos: single cell reprogramming in two phases. Cell Stem Cell 11 445-447. (doi:10.1016/j.stem.2012.09.004)

Park IH, Zhao R, West JA, Yabuuchi A, Huo HG, Ince TA, Lerou PH, Lensch MW \& Daley GQ 2008 Reprogramming of human somatic cells to pluripotency with defined factors. Nature 451 141-146. (doi:10.1038/ nature06534)

Plath K \& Lowry WE 2011 Progress in understanding reprogramming to the induced pluripotent state. Nature Reviews. Genetics 12 253-265. (doi:10.1038/nrg2955)

Polo JM, Liu S, Figueroa ME, Kulalert W, Eminli S, Tan KY, Apostolou E, Stadtfeld M, Li Y, Shioda T et al. 2010 Cell type of origin influences the molecular and functional properties of mouse induced pluripotent stem cells. Nature Biotechnology 28 848-855. (doi:10.1038/nbt.1667)

Rafei M, Hsieh J, Fortier S, Li M, Yuan S, Birman E, Forner K, Boivin MN, Doody K, Tremblay M et al. 2008 Mesenchymal stromal cell-derived CCL2 suppresses plasma cell immunoglobulin production via STAT3 inactivation and PAX5 induction. Blood 112 4991-4998. (doi:10.1182/ blood-2008-07-166892)

Rege TA \& Hagood JS 2006 Thy-1 as a regulator of cell-cell and cell-matrix interactions in axon regeneration, apoptosis, adhesion, migration, cancer, and fibrosis. FASEB Journal 20 1045-1054. (doi:10.1096/fj.05-5460rev)

Rodriguez AM, Pisani D, Dechesne CA, Turc-Carel C, Kurzenne JY, Wdziekonski B, Villageois A, Bagnis C, Breittmayer JP, Groux H et al. 2005 Transplantation of a multipotent cell population from human adipose tissue induces dystrophin expression in the immunocompetent mdx mouse. Journal of Experimental Medicine 201 1397-1405. (doi:10. 1084/jem.20042224)

Rodriguez A, Allegrucci C \& Alberio R 2012 Modulation of pluripotency in the porcine embryo and iPS cells. PLoS ONE 7 e49079. (doi:10.1371/ journal.pone.0049079)

Sackstein R, Merzaban JS, Cain DW, Dagia NM, Spencer JA, Lin CP \& Wohlgemuth R 2008 Ex vivo glycan engineering of CD44 programs human multipotent mesenchymal stromal cell trafficking to bone. Nature Medicine 14 181-187. (doi:10.1038/nm1703)

Safford KM, Hicok KC, Safford SD, Halvorsen YD, Wilkison WO, Gimble JM \& Rice HE 2002 Neurogenic differentiation of murine and human adipose-derived stromal cells. Biochemical and Biophysical Research Communications 294 371-379. (doi:10.1016/S0006-291X(02)00469-2)

Silva J, Barrandon O, Nichols J, Kawaguchi J, Theunissen TW \& Smith A 2008 Promotion of reprogramming to ground state pluripotency by signal inhibition. PLoS Biology 6 e253. (doi:10.1371/journal.pbio.0060253)
Silva J, Nichols J, Theunissen TW, Guo G, van Oosten AL, Barrandon O, Wray J, Yamanaka S, Chambers I \& Smith A 2009 Nanog is the gateway to the pluripotent ground state. Cell 138 722-737. (doi:10.1016/j.cell. 2009.07.039)

Spaggiari GM, Abdelrazik H, Becchetti F \& Moretta L 2009 MSCs inhibit monocyte-derived DC maturation and function by selectively interfering with the generation of immature DCs: central role of MSC-derived prostaglandin $\mathrm{E}_{2}$. Blood 113 6576-6583. (doi:10.1182/blood-2009-02203943)

Sridharan R, Tchieu J, Mason MJ, Yachechko R, Kuoy E, Horvath S, Zhou Q \& Plath K 2009 Role of the murine reprogramming factors in the induction of pluripotency. Cell 136 364-377. (doi:10.1016/j.cell. 2009.01.001)

Stadtfeld M \& Hochedlinger K 2010 Induced pluripotency: history, mechanisms, and applications. Genes and Development 24 2239-2263. (doi:10.1101/gad.1963910)

Sullivan GJ, Bai Y, Fletcher J \& Wilmut I 2010 Induced pluripotent stem cells: epigenetic memories and practical implications. Molecular Human Reproduction 16 880-885. (doi:10.1093/molehr/gaq091)

Takahashi K \& Yamanaka S 2006 Induction of pluripotent stem cells from mouse embryonic and adult fibroblast cultures by defined factors. Cell 126 663-676. (doi:10.1016/j.cell.2006.07.024)

Tobita M, Orbay H \& Mizuno H 2011 Adipose-derived stem cells: current findings and future perspectives. Discovery Medicine 11 160-170.

Trivedi HL, Vanikar AV, Thakker U, Firoze A, Dave SD, Patel CN, Patel JV, Bhargava AB \& Shankar V 2008 Human adipose tissue-derived mesenchymal stem cells combined with hematopoietic stem cell transplantation synthesize insulin. Transplantation Proceedings 40 1135-1139. (doi:10.1016/j.transproceed.2008.03.113)

Wei C, Liu X, Tao J, Wu R, Zhang P, Bian Y, Li Y, Fang F \& Zhang Y 2013 Effects of vitamin $C$ on characteristics retaining of in vitro-cultured mouse adipose-derived stem cells. In Vitro Cellular \& Developmental Biology. Animal 50 75-86. (doi:10.1007/s11626-013-9673-6)

West FD, Uhl EW, Liu Y, Stowe H, Lu Y, Yu P, Gallegos-Cardenas A, Pratt SL \& Stice SL 2011 Brief report: chimeric pigs produced from induced pluripotent stem cells demonstrate germline transmission and no evidence of tumor formation in young pigs. Stem Cells 29 1640-1643. (doi:10.1002/stem.713)

Yanez R, Lamana ML, Garcia-Castro J, Colmenero I, Ramirez M \& Bueren JA 2006 Adipose tissue-derived mesenchymal stem cells have in vivo immunosuppressive properties applicable for the control of the graft-versus-host disease. Stem Cells 24 2582-2591. (doi:10.1634/ stemcells.2006-0228)

Yu J, Vodyanik MA, Smuga-Otto K, Antosiewicz-Bourget J, Frane JL, Tian S, Nie J, Jonsdottir GA, Ruotti V, Stewart R et al. 2007 Induced pluripotent stem cell lines derived from human somatic cells. Science $\mathbf{3 1 8}$ 1917-1920. (doi:10.1126/science.1151526)

Zhang Y, Wei C, Zhang P, Li X, Liu T, Pu Y, Li Y, Cao Z, Cao H, Liu Y et al. 2014 Efficient reprogramming of naive-like induced pluripotent stem cells from porcine adipose-derived stem cells with a feeder-independent and serum-free system. PLOS ONE 9 e85089. (doi:10.1371/journal.pone. 0085089)

Zhou N, Cao Z, Wu R, Liu X, Tao J, Chen Z, Song D, Han F, Li Y, Fang F et al. 2014 Dynamic changes of histone H3 lysine 27 acetylation in preimplantational pig embryos derived from somatic cell nuclear transfer. Animal Reproduction Science 148 153-163. (doi:10.1016/j.anireprosci. 2014.06.002)

Zhu W, Shi XL, Xiao JQ, Gu GX, Ding YT \& Ma ZL 2013 Effects of xenogeneic adipose-derived stem cell transplantation on acute-onchronic liver failure. Hepatobiliary \& Pancreatic Diseases International 12 60-67. (doi:10.1016/S1499-3872(13)60007-7)

Received 10 August 2014

First decision 13 October 2014

Revised manuscript received 15 January 2015

Accepted 2 February 2015 